\title{
Mulher também pode: Histórias de Vida no futebol
}

\author{
Women can also: Life History in Soccer
}

\author{
Claudia-Yaneth Martínez-Mina \\ Corporación Universitaria del Caribe CECAR. Facultad de Humanidades y \\ Educación, Programa de Trabajo Social. Sincelejo, Colombia. \\ $\triangle$ cwa0708@hotmail.com \\ https://orcid.org/0000-0003-1093-9161
}

Recibido: 14-09-2019

Aceptado: $20-11-2019$

\section{RESUMO}

Como resultado de uma pesquisa qualitativa, e considerando os argumentos teóricos dos Estudos Culturais e Estudos de Gênero em seus aspectos pós-estruturalistas, este artigo analisa as experiências das jogadoras da equipe de futsal da Universidade Federal do Rio Grande do Sul (UFRGS), identificando a forma como a categoria relacional de gênero apareceu nos diferentes contextos sociais, em função de serem mulheres que praticavam futebol. Com base na contribuição teórica e metodológica da História Oral, foram realizadas entrevistas sobre as histórias de vida de quatorze jogadoras, participantes da equipe universitária em 2014. Foi possível identificar quatro categorias de análise: a maneira como as jogadoras iniciaram o esporte do futebol; as características do futebol no contexto escolar; a participação esportiva das jogadoras em relação ao futebol; e os significados que as jogadoras atribuíram à prática do futebol. As conclusões arrojaram a influência das normas de gênero, no desenvolvimento das habilidades esportivas, e nas possiblidades de participação a nível competitivo. De igual forma, a importância das aulas de educação física baseadas no respeito à diversidade, mesmo de gênero, como um desafio no âmbito escolar. Finalmente, os significados atribuídos à prática esportiva, foram relacionadas com sociabilidade, paixão, amizade, e lutas políticas em torno a serem mulheres.

Palavras-chave: Soccer; Mulheres; Gênero; Esporte; História oral.

\section{ABSTRACT}

As a result of a qualitative research, and considering the theoretical arguments of Cultural Studies and Gender Studies in its poststructuralist aspects, this article analyzes the experiences of the players of the futsal team of the Federal University of Rio Grande do Sul (UFRGS), identifying how the relational category of gender appeared in the different social contexts, due to being women who played soccer. Based on the theoretical and methodological contribution of Oral History, interviews were conducted on the life histories of fourteen female players, participating in the university team in 2014. It was possible to identify four categories of analysis: the way female players 
started the sport of soccer; the characteristics of soccer in the school context; the sports participation of the players in relation to soccer; and the meanings that the players attributed to the practice of soccer. The conclusions boldly influenced the influence of gender norms on the development of sports skills and the possibilities for participation at a competitive level. Similarly, the importance of physical education classes, based on respect for diversity, even of gender, as a challenge in the school environment. Finally, the meanings attributed to sports were related to sociability, passion, friendship, and political struggles around being women.

Keywords: soccer; women; genre; Sport; oral history.

\section{INTRODUÇÃO}

A construção social de gênero também se manifesta na prática de esportes, desde a infância. Os esportes, assim como outras manifestações de cultura, são generificados, o que significa que alguns são considerados socialmente mais adequados para as mulheres e outros mais para os homens. O exposto anteriormente, toma como referência uma representação social de gênero, na qual se enfatizam diferentes qualidades em homens e mulheres; e, como norma implícita, estas devem permanecer dentro das fronteiras entre o feminino e o masculino (Louro, 2000). As histórias de vida das jogadoras da equipe de futsal da Universidade Federal do Rio Grande do Sul (UFRGS) foram vistas com projeção a ser investigadas, como resultado dos diálogos informais na interação cotidiana, em que manifestaram as dificuldades por serem mulheres que jogam ou jogavam futebóis, com ênfase especial nas questões relacionadas à categoria de gênero. O termo futebóis foi usado neste estudo para fazer referência ao fato das jogadoras realizarem esporte através de uma bola nos pés, o qual inclui os esportes mencionados por suas falas derivados do futebol. Sendo difícil especificar nas suas trajetórias esportivas, cada esporte como um particular, se optou por usar este termo exposto inicialmente por Damo (2007), em diversas matrizes, integrando, além da explicação do autor, os diversos espaços nos quais elas praticaram tanto futebol, como futsal, assim como futebol sete, sem a rigidez de institucionalização que estes esportes precisam para serem nomeados como tais.

Alguns estudos sobre as categorias identificadas nesta pesquisa, com relação à inserção das mulheres na prática esportiva, a experiência com o esporte na escola, e os significados atribuídos à prática esportiva foram indagados anteriormente, tais como Joras (2015); Mota (2014); Araujo e Silveira (2013); Fernandes e Mourão (2013); Altmann e Reis (2013); Wenetz, Stigger e Meyer (2013); Dornelles (2011); Moreira e Cunha (2008); Silveira (2008); Goellner (2007); Souza e Altmann (1999) entre outros. Estas pesquisas têm identificado um retraso nos processos de formação, devido à ausência de escolinhas de base para as mulheres que praticam futebol. De igual forma, um controle com relação à construção da feminilidade, do modo que, as resistências pelo jogo do futebol, apareceram desde crianças, sendo este um aspecto comum nas histórias das atletas.

A construção social do gênero se manifesta também no espaço esportivo através das representações de gênero que surgem e são enfatizadas sutilmente nas mulheres/ meninas quando praticam os futebóis. O período de realização da pesquisa iniciou no ano 2014, por meio das observações junto ao grupo. Paralelamente, foi necessário fazer o envolvimento teórico sobre as questões de gênero no esporte, a partir da visão dos Estudos Culturais e dos Estudos de Gênero Feministas em suas vertentes pósestruturalistas. Depois de se indagar sobre a construção social do gênero, e a forma como se manifesta no espaço esportivo, como por exemplo, as desigualdades entre homens e mulheres nesse espaço, assim como as representações de gênero que surgem e são 
enfatizadas sutilmente nas mulheres/meninas quando praticam os futebóis, emergiu a questão norteadora desta pesquisa: Quais são as experiências das atletas de futsal da Universidade Federal do Rio Grande do Sul, em sua trajetória com os futebóis e como a categoria de gênero apareceu nos diversos contextos sociais, vivenciados em função de serem mulheres que praticavam este esporte?

Pesquisas como esta são necessárias para visibilizar as mulheres no campo do esporte, aportando assim nas histórias das mulheres no âmbito dos futebóis. A partir da realidade do futsal como um esporte com hegemonia masculina, as jogadoras entrevistadas reconstruíram suas histórias como protagonistas de sua própria trajetória esportiva. Utilizou-se a técnica da história oral, entendendo que "a força da História Oral, todos sabemos, é dar voz àqueles que normalmente não a têm: os esquecidos, os excluídos" (Joutard, 2000, p.33). Tal afirmação no caso das atletas, o fato de serem mulheres as coloca em uma situação de subordinação em um contexto que ainda considera este esporte como apto para os homens, e menos adequado para as mulheres. É evidente que, as histórias das mulheres no campo do futebol devem ser descobertas, como uma estratégia política que permita o reconhecimento das atletas que praticam os futebóis.

Por esse motivo, se pensou adequado realizar uma pesquisa com mulheres, jogadoras dos futebóis desde a infância e que estivessem praticando ativamente o futsal em algum clube ou time, o que significaria uma continuidade relativa na prática dos futebóis desde crianças até a atualidade, encontrando como idôneo para este estudo o time de futsal da Universidade Federal do Rio Grande do Sul (UFRGS).

\section{METODOLOGIA}

Este estudo é qualitativo de tipo narrativo, devido a que possibilitou a recolecção de informação sobre as experiências de vida das atletas, a partir de um tópico particular: a prática esportiva dos futebóis desde seus inícios até o momento de fazer as entrevistas (Hernández-Sampieri, Fernández-Collado, \& Baptista-Lucio, 2010). O método implementado foi a História Oral, a qual consiste em converter uma entrevista em uma fonte escrita, explicado por Goellner; Muhlen; Maurmann; e Romero (2007). Segundo os autores, o primeiro passo para transformar um relato oral em uma fonte escrita é a preparação da entrevista. Aqui as jogadoras foram contactadas, convidadas a participar na pesquisa, foi estabelecido o dia e a hora da entrevista, ao mesmo tempo que era elaborado e preparado o roteiro de perguntas a utilizar na entrevista. 0 instrumento utilizado foi uma guia de perguntas para fazer a entrevista semiestruturada, o que permitiu construir antecipadamente perguntas abertas, que dariam respostas ao que se pretendia investigar na pesquisa, permitindo que as atletas falassem sobre as experiências que consideravam importantes para serem contadas. A pergunta inicial, você lembra a primeira vez que teve uma bola nos pés? Promoveu o diálogo aberto, bem como a oportunidade de aprender sobre uma parte de suas histórias de vida. A segunda etapa do processo, consistiu na execução e gravação das entrevistas. Estas foram realizadas dentro da Escola de Educação Física da UFRGS, porque a maioria das entrevistadas estudava lá, ou porque tinham os treinos naquela escola, o que facilitou o encontro para as entrevistas. Antes de iniciar as entrevistas, as jogadoras assinaram uma carta de cessão e preencheram um formulário com todos os seus dados pessoais como parte das considerações éticas da pesquisa.

A terceira etapa do processo, consistiu na transcrição das entrevistas à medida que eram narradas. Posteriormente, e como quarto passo, a entrevista foi processada. Aqui foi necessário revisá-las e compará-las com outras fontes. Este procedimento era necessário quando, por exemplo, nas entrevistas, as jogadoras mencionavam pessoas, lugares, 
campeonatos etc., e era necessário especificar numa nota de rodapé mais informação a este respeito. Nesta fase, os erros comunicativos também foram examinados, e a respectiva correção foi feita sem alterar o significado de suas palavras. Como quinta etapa, as entrevistas, já convertidas em fonte escrita, foram devolvidas às jogadoras, a fim de serem revisadas por elas uma última vez antes de iniciar a análise, de modo que excluíssem, caso considerassem necessário, as informações que, segundo seus critérios, não fossem pertinentes para serem publicadas. Finalmente, após o retorno das entrevistas, iniciou-se a categorização e análise das informações, com o auxílio do programa Atlas Ti.

Finalmente, foi realizada uma leitura e releitura já nas fontes orais transcritas, com o objetivo de encontrar, a partir da visão da perspectiva de gênero, o que Ferrarotti (2011) nomeou como as "áreas problemáticas", as quais surgiram quando as atletas narraram seus inícios na prática dos futebóis, na qual as representações de gênero se fizeram presentes nos diferentes espaços sociais à causa desta atividade. A análise da informação foi feita a partir da análise de conteúdo (Bardin, 1986). Se identificaram quatro categorias: a forma como as atletas se inserira na prática esportiva dos futebóis; as características do contexto escolar, com relação aos futebóis; a participação esportiva das atletas desde crianças; e os significados que as atletas atribuíram à prática dos futebóis.

As participantes da pesquisa foram quatorze das jogadoras que estão participando no time de futsal da UFRGS, a partir da sua reconstrução no ano de 2007, e a mãe de uma das jogadoras mais antigas. Este time foi escolhido, principalmente, porque as atletas que faziam parte do time da UFRGS, começaram sua trajetória com os futebóis desde crianças; além disso, estavam participando ativamente das competições, sendo atletas comprometidas com a equipe. As atletas entrevistadas tinham 17 e 28 anos de idade, sendo que a mais velha passou a ser treinadora do time no ano 2015. Perguntou-se para todas as jogadoras que treinavam frequentemente no time se queriam participar da pesquisa, cuja média de participantes era aproximadamente de 17 jogadoras, pois a assistência continuada aos treinos indicava seu compromisso com o time, sendo este um dos critérios para escolher as participantes. Nem todas as atletas que participavam continuamente dos treinos foram entrevistadas, somente as que mostraram um interesse e aceitaram o convite. As entrevistas realizadas fazem parte do Projeto Garimpando Memórias do Centro de Memória do Esporte (CEME), da Escola de Educação Física da Universidade Federal do Rio Grande do Sul, cujo procedimento se fundamenta nas orientações teórico-metodológicas da História Oral. Para coletar as informações, foram realizadas 18 entrevistas, sendo entrevistadas 14 pessoas no total, já que uma das atletas foi entrevistada três vezes, e outra em duas ocasiões.

\section{RESULTADOS}

Segundo os relatos das atletas entrevistadas da equipe da UFRGS, o primeiro contato com uma bola de futebol apareceu em forma de brincadeira: na rua, no pátio da casa, na garagem ou em qualquer espaço onde fosse possível levar à prática este jogo ${ }^{1}$. Estes momentos de lazer presentes na infância das atletas que integram a equipe da UFRGS, nos quais o futebol foi protagonista, caracterizou-se pela companhia de meninos na sua maioria, o que Ihes possibilitou a aproximação com uma atividade esportiva que,

1. A exceção de uma das atletas, quem a seus seis anos de idade conheceu o futsal na escola, quando observou umas crianças, um grupo misto, jogando no ginásio, como foi relatado por ela: "Eu disse para meu pai: 'Pai, eu quero que tu vá à escola amanhã e veja o que eu vi no ginásio'. (...) Ele viu e eu disse para ele que era aquilo ali que eu queria fazer. Ele disse: 'No ano que vem, tu sais da ginástica e joga bola'"' (BERTOLI, 2014). 
socialmente, é considerada masculina: "Como eu tenho um irmão mais velho, guri, é normal gostar de jogar bola. Daí eu sempre fui muito apegada a ele, então, como ele é guri e gosta de jogar bola, aí acabava mais ligando a ele" (T. Fagundes, comunicação pessoal, 30 de junho de 2015). Esta situação foi vivenciada pelas atletas, as quais manifestaram serem as únicas meninas no jogo, algumas com a companhia excepcional de mais uma ou duas meninas, especialmente nos seus primeiros contatos com a bola quando o futebol era praticado nos espaços de lazer, "era bem engraçado porque eu era a única menina que jogava e muitas vezes jogava melhor que os meninos" (L. Andrade, comunicação pessoal, 25 de maio 2015).

Por outro lado, as atletas, sendo meninas, vivendo e produzindo as suas feminilidades, lidaram com as contradições que as representações normatizadas de feminilidade Ihes ocasionava: jogar futebol as fazia ver e sentir como "diferentes", não apenas entre o grupo de meninos com os que se relacionavam para praticá-lo, mas também, das outras meninas que não gostavam dele. Como foi relatado por uma das atletas:

Havia algumas situações que eu me sentia um pouco, digamos excluída ou diferente (...). É que me sentia assim "será que eu estou no lugar certo?", até porque as vizinhas passavam e ficavam olhando e até mesmo falavam algumas palavras assim, do tipo "tu parece um guri, no meio dos guris", "tu tem que fazer coisas de menina", "não tem que ficar jogando futebol" (S. Ramos, comunicação pessoal, 17 de abril de 2015).

Outra das jogadoras do time da UFRGS descreve a sua experiência de jogar só com meninos como meio estranha, porque era só ela no meio de muitos meninos (T. Fagundes, comunicação pessoal, 30 de junho de 2015).

Os diálogos relacionados com as vivências das atletas, que referem seu primeiro encontro com o futebol, é protagonizado pelo apoio familiar dos pais e de alguns parentes próximos a elas, especialmente tio, avô e irmãos. Esta contribuição familiar, em relação à prática do futebol, teve um papel importante na apropriação e na continuidade da prática esportiva das atletas nos diversos espaços, como escola, escolinhas, clubes e na equipe da universidade. As atletas entrevistadas narraram a forma como seus parentes procuraram escolinhas de futebol ou de futsal para elas continuarem jogando, aprendendo e ampliando suas possibilidades de participação.

Quando eu tinha cinco anos, eu jogava só com os meninos e o meu tio viu que eu jogava um pouquinho bem e falou para a minha mãe: "olha, quem sabe tu não botas ela numa escolinha de futebol?" E a minha mãe procurou uma escolinha que tivesse só de meninas e de futsal, e não tinha na época (R. Espirito Santo, comunicação pessoal, 02 de julho de 2015).

Do mesmo modo, todas as atletas da equipe de futsal da UFRGS manifestaram terem sido apoiadas pela família, embora este apoio fosse diferente para cada uma. O apoio se apresentou na procura de uma escolinha de futebol ou futsal, pagando os gastos demandados pela escolinha, indo para assistir os jogos e competições, jogando bolas com elas, apoiando-as emocionalmente, oferecendo conselhos sobre as decisões relacionadas com o futebol entre outros. O apoio da família se constitui como um aspecto importante na continuidade da prática esportiva.

Ela nunca me proibiu de ficar na rua jogando futebol com os guris, e até mesmo me incentivava, tanto que foi a partir dela que eu entrei para uma escolinha. Sempre foi minha maior incentivadora, a minha mãe (S. Ramos, comunicação pessoal, 17 de abril de 2015). 
Por outro lado, algumas situações de resistência se evidenciaram mais que tudo em parentes mulheres das jogadoras, o que indica que as primeiras barreiras com que as atletas se depararam, se relacionaram com a aceitação familiar do futebol, como se observa no seguinte relato:

Minha mãe nesse tempo era mais ausente em relação à motivação, de apoiar, porque ela achava que não era lugar de menina jogar, aquele preconceito de que menina tinha que ficar em casa, jogando vôlei, brincando de boneca, mas ela nunca desejou mal (V. Polese, comunicação pessoal, 22 de maio de 2015).

Todas essas experiências das atletas com suas famílias, fazem parte de suas histórias de vida no futebol.

Com relação ao âmbito escolar, as atletas de futsal da UFRGS relataram suas experiências dentro da escola, como praticantes dos futebóis, especialmente no recreio, nas aulas de Educação Física, e nos treinos de futsal. Nessas narrativas foi possível analisar a forma como as relações de gênero permeiam e são construídas dentro dos espaços escolares, particularmente no momento de brincar ou praticar esportes, e como essas relações de poder são resistidas, aceitas e disputadas.

No ensino fundamental, e a partir dos seis anos de idade, doze das quatorze atletas entrevistadas se apropriaram do recreio para mostrar suas habilidades futebolísticas na companhia de meninos, esta foi concebida como uma resistência ao poder. Do mesmo modo, nesse espaço escolar se evidenciava a segregação instantânea; as meninas praticavam vôlei ou handebol, enquanto os meninos jogavam futebol. A segregação parecia ser natural, guiada tanto por gênero, como por interesses. Uma das atletas entrevistadas fazendo referência ao momento do recreio expressou: "eles liberavam a bola e os meninos jogavam, e os meninos sempre me chamavam inclusive de turmas diferentes da minha" (L. Machado, comunicação pessoal, 30 de junho de 2015b).

Nos relatos das atletas se faz evidente uma separação nas aulas de Educação Física, em algumas a partir da $5^{a}$ série; outras desde séries anteriores; experiências que aconteceram a partir de $1993^{2}$. Essa segregação consistia em que meninos e meninas realizassem esportes de modo separado, pressupondo corpos diferentes por "natureza", mas também, esportes diferentes, ou seja, generificados. Do mesmo modo, se observou a preferência de parte das colegas das atletas entrevistadas, para realizar esportes distintos ao futsal:

Ele (o professor) pegava a bola e dava e a gente jogava. Às vezes as gurias não queriam, então, (...) ela (a professora) pegava a bola de vôlei e a de futsal, e aí ela fazia assim, botava uma em cada mão e falava: 'as gurias se quiserem, os guris se quiserem (T. Fagundes, comunicação pessoal, 30 de junho de 2015).

Ante tais métodos de ensino, as atletas relataram as estratégias por elas adoptadas nessas aulas, tanto no ensino médio como fundamental, como, por exemplo, incentivar a prática do futebol nas suas colegas:

Eu tentava fazer com que elas participassem muito, passava bastante a bola para elas, eu não tentava fazer, acho que, monopolizar o jogo, (...) mas eu sempre tentei ajudar e tentar até ensinar elas a fazer, como passar, como chutar, tentei também de algumas formas (L. Machado, comunicação pessoal, 30 de junho de 2015b).

2. A data de nascimento das atletas entrevistadas vai desde 1987 até 1997 . Isso situa sua inserção no ensino fundamental, a partir dos 6 anos de idade, desde 1993. 
Outra estratégia consistiu em participar das aulas de Educação Física juntamente com os meninos: "Eu fazia a Educação Física na quadra dos meninos, para jogar futsal, e as gurias faziam a Educação Física delas" (R. Giozza, comunicação pessoal, 04 de dezembro de 2014). Ou por exemplo, como se observa no seguinte relato:

No meu ensino médio eu me revoltei, no ensino médio eram turmas separadas, Educação Física tinha um professor para os guris e uma professora para as gurias, e eu não aguentava mais, no terceiro ano eu falei: "não, eu quero fazer aula com os guris", porque a aula das gurias era sempre handebol ou dança, e os guris jogavam basquete, jogavam futebol, corriam e eu queria fazer aquilo. E aí, no terceiro ano, eu pedi para a minha professora, fui até no diretor da escola pedir liberação para ir para a turma dos guris porque eu não queria mais fazer sempre aquilo, queria mudar também (R. Máximo, comunicação pessoal, 11 de junho de 2015).

As resistências adotadas por algumas atletas nas aulas de Educação Física abriram espaços de aceitação para o futebol nesses contextos particulares. Sua ousadia gerou mudanças paulatinas, mas importantes, pois outras meninas se sentiram incentivadas, tomando-as como referência: "A partir disso, teve gurias dentro do colégio que começaram a jogar futebol, porque viram, ah! Se tem uma menina jogando com os guris, porque eu não posso?" (V. Polese, comunicação pessoal, 22 de maio de 2015).

Nas narrativas sobre suas vivências mais significativas dentro do contexto escolar, os campeonatos nos que participaram ${ }^{3}$ as influenciaram a desenvolver atributos da personalidade tais como a liderança, a responsabilidade e a disciplina. Nos seus relatos as atletas evidenciam que em diversas ocasiões eram as pessoas mais interessadas em participar das competições, assumindo muitas vezes a função de criar e organizar os times, ou seja, eram protagonistas dentro e fora do campo inclusive tomando a iniciativa de realizar a competições. Esses testemunhos permitem observar seus esforços ou as estratégias orientadas também para criar as circunstâncias que permitissem a sua participação nos espaços escolares. Vejamos:

A gente tinha que preparar a equipe, tinha que falar com o professor, levar a equipe para o professor [...] Mas a gente tinha que correr atrás bastante das coisas, tinha que montar equipe, chamar o pessoal para treinar, essas coisas assim era mais a gente que fazia (J. Machado, comunicação pessoal, 08 de junho de 2015).

Observou-se que várias das atletas participaram de escolinhas de meninos devido à dificuldade para encontrar espaços direcionados especificamente para meninas com vontade de jogar futebol.

Do mesmo modo, seis das atletas participaram no Campeonato Gaúcho de Futsal Feminino, que é considerada a máxima competição do Estado Rio Grande do Sul. Suas experiências como jogadoras dentro desses times considerados "profissionais", não foram diferentes das que atravessam o futebol praticado por mulheres nesse estado, como foi narrado por uma das atletas:

Por enquanto, não pretendo jogar mais estadual, porque não tem esse reconhecimento. Parece que é um jogo, só porque é jogo de mulher, não tem TV, não tem reportagem, não tem nada. Ainda mais a questão de cuidados, porque em 2012 eu torci o joelho e não tive auxilio nenhum, tanto do time. Eu tive que me virar sozinha (V. Polese, comunicação pessoal, 22 de maio de 2015).

\footnotetext{
3. As principais competições extraescolares mencionadas pelas atletas, as quais fizeram parte das suas primeiras experiências de participação em um time específico de futsal foram: os Jogos Escolares do Rio Grande do Sul (JERGS) de caráter público, a Estudantil - Paquetá Esportes Adidas, a Copa Disney, Guri Bom de Bola, School Games, Campeonato de Verão (especificamente nas cidades pequenas) e os Jogos Abertos de Porto Alegre. Também mencionaram a participação em algumas competições internas exclusivas para as estudantes de escolas ou clubes específicos, como os Jogos Estudantis Luteranos, o Maristão, os Jogos Acemistas Brasileiros, os Jogos Vicentinos e as Olimpíadas do Colégio de Aplicação.
} 
Com relação aos significados da prática esportiva dos futebóis se percebeu que os futebóis, ou o esporte em geral, influiu na maioria delas para a tomada das decisões relevantes da vida, como por exemplo, o que estudar, visto que das quatorze atletas entrevistadas, dez cursaram ou estão cursando Educação Física. Uma das atletas entrevistadas comentou: "Tudo que eu tenho, é o futebol, os amigos que eu tenho, aonde eu estou morando agora, o curso que eu estou fazendo, é tudo pelo futsal, por causa dele (J. Machado, comunicação pessoal, 08 de junho de 2015).

Uma expressão informal usada por pessoas internas e externas ao time para fazer referência ao processo de participação das integrantes, é a denominada "panela". Esse evento foi mencionado por algumas das atletas entrevistadas nos processos de interação no interior do time da UFRGS: "Algumas pessoas falavam "não, a equipe da UFRGS é uma panela é difícil de entrar, tu não consegues" (J. Machado, comunicação pessoal, 08 de junho de 2015).

Ser parte da "panela" adquire diferentes significados dependendo de quem fala. Dentro do time, surgem outras "panelas", que estão mais relacionadas com as pessoas com as que criaram laços mais fortes de amizade.

Para algumas das jogadoras da equipe da UFRGS, o esporte Ihes possibilitou a criação de maiores vínculos de amizade dos gerados, com pessoas dos seus outros círculos sociais, como foi observado no relato a seguir: "É bem diferente que nem quando eu estou no meu curso, na minha faculdade, eu não me vejo me dando tão bem com as minhas colegas como eu me dou bem com o pessoal aqui" (R. Máximo, comunicação pessoal, 11 de junho de 2015).

Evidenciou-se também intencionalidades políticas relacionadas com a luta das mulheres para conquistar esse espaço marcado socialmente como para homens. Desmistificar crenças relacionadas a suas capacidades e possibilidades como mulheres através da prática esportiva do futsal é uma luta que foi constituindo-se por meio das suas experiências de exclusão, das dificuldades encontradas nas suas trajetórias e vivências pessoais com os futebóis. O futebol foi visto como um espaço de luta feminista, ali as mulheres lutaram não só para jogar, treinar, competir, mas antes de tudo para serem reconhecidas como atletas. Este sentido de luta se percebe no relato de uma das atletas ante a pergunta, o que significa para você ser mulher que joga futsal?

Eu acho que é mais para mostrar que mulher também pode, tipo, não existe isso, de um esporte ser masculino, outro feminino, acho que vai muito além. Mostrar que não é porque a gente é mulher que não pode jogar, que não pode lutar, que não pode, entendeu (Ribas, comunicação pessoal, 04 de julho de 2015).

Mulher também pode, palavras que refletem o caráter político observado na fala de algumas das atletas aqui entrevistadas, mas também é o nome da música escrita e composta por elas mesmas, tocada através da banda de pagode fundada exclusivamente com integrantes do time. Essa banda é outro resultado da associação esportiva, que leva consigo uma identidade de grupo como jogadoras de futsal e como mulheres. O grupo Samba Delas ${ }^{4}$ é uma manifestação pública de sua sociabilidade como equipe, e uma forma de expor ao mundo suas percepções e lutas políticas de gênero. A seguir uma parte da letra da música Mulher também pode: Eu vou mandar um recado pra você que

4. O grupo Samba Delas, no início teve o nome de UFRGSamba, mas posteriormente as atletas integrantes da banda começaram a tocar fora da universidade, pelo que com a votação de várias pessoas da universidade foi escolhido o novo nome. Atualmente este grupo de pagode toca em diversos lugares públicos, foram entrevistadas pela rádio e televisão, e são convidadas a eventos tanto relacionados à universidade como fora dela. 
sai falando que mulher tem que limpar e ficar cozinhando. Ceva, futebol e pagode quem não gosta? Mulher também pode, vamos fazer uma aposta. (Samba Delas, 2015). ${ }^{5}$

Sem importar o pensamento predominante da sociedade sobre as mulheres que praticam os futebóis, as atletas entrevistadas narraram a forma como se mantiveram em frente, mesmo, com a intenção de conquistar o espaço. A sociabilidade resultante dessa prática complementa suas vidas como mulheres, como esportistas e como universitárias. Os desafios, as batalhas empreendidas desde que começaram a praticá-lo fez delas o que hoje são, enfatizando que nestas experiências é possível achar o caráter educativo do esporte, ou seja, um aprendizado de vida.

\section{DISCUSSÃO}

Visto que o futebol é considerado como um esporte que reafirma a identidade masculina, usualmente são incentivadas outras práticas esportivas para as meninas, especialmente com a indicação, segundo Goellner (2007), de não se afastar da "graciosidade, a delicadeza e a beleza, atributos colados a uma suposta 'essência feminina" (p. 185). Desse modo, o esporte se configura como um instrumento de generificação, que propicia a sub-representação de mulheres em algumas modalidades, particularmente aquelas que requerem, para seu desempenho, atributos socialmente relacionados com a masculinidade, tais como força, agressividade, coragem, não esperados para as mulheres, como é o caso do futebol. Alguns estudos indicam que, para ter sucesso no esporte, é necessário o uso de atributos tais como força, agressão e competição (Hall, 1996; Hargreaves, 1990; Lenskyj, 1994; Mckay, 1997 apud Shaw, 2007). Estas características têm sido associadas culturalmente à masculinidade, visto que, regularmente, são incentivadas outras práticas esportivas nas meninas, que concordem com o que se considera feminino na cultura, que na maioria dos casos, representa de maneira predominante valores em oposição, relacionados à fragilidade, ao mesmo tempo que, simbolicamente, reforçam uma inferioridade física culturalmente vista como "natural".

O feminismo, baseado na corrente teórico-filosófica do pós-estruturalismo (a qual faz uma crítica à modernidade e questiona a racionalidade ocidental, especialmente o binarismo e etnocentrismo, tomando como referência o conceito de desconstrução de Jacques Derrida), deu lugar ao chamado feminismo pós-estruturalista que trabalha na desconstrução da categoria sexo-gênero, a diferença do feminismo cultural e liberal, os quais ressaltavam a importância da mulher recuperar uma suposta essência feminina, subjugada pelo patriarcado, ou seja, uma feminilidade redefinida (Zambrini e Ladevito, 2009). A partir dessa visão, a identidade feminina começa a ser estudada levando em conta a experiência subjetiva, assim como os discursos sociais. Posteriormente, outras ideias feministas, desenvolvidas especialmente por Judith Butler e Teresa de Lauretis, integraram a esta noção a crítica foucaultiana, apontando que onde há poder há resistência, e que estas resistências são ambíguas, assim como enfatizaram na construção da identidade de gênero segundo as experiências, a história, e o contexto sociocultural (Zambrini e Ladevito, 2009). Sendo assim, o conceito de gênero, se usa como categoria de análise das relações sociais entre homens e mulheres, e como um marcador de identidade social.

Scott (1986 citado em Louro, 1997) aponta que nas sociedades, o gênero se compreende de forma dicotômica e polarizada, na qual homem e mulher são considerados polos opostos, e essa seria a única forma de relação entre os dois elementos. Dessa forma, 
as atletas lidaram com essa sensação de diferença, produzida pelo olhar dos outros, conflitando o que elas eram, e o que elas sentiam que eram, com o que os outros achavam que elas eram. A visão de feminilidade, imposta às atletas desde crianças, reafirmou as relações de poder e a normalização da desigualdade entre os gêneros. Esta situação se evidenciou na socialização dentro da família, na escola, nas aulas de educação física, e mesmo, nas estruturas como está organizado o esporte.

Neste ponto, sua identidade de gênero, construída com base nas suas experiências com o esporte, chocava com o normatizado socialmente das feminilidades, com a construção social do gênero, o que provocaria nelas se perguntar "será que estou no lugar certo?" (S. Ramos, comunicação pessoal, 17 de abril de 2015). Aqui é importante mencionar a pluralidade da construção da identidade com relação ao gênero (Louro, 1997); não existe uma única forma de ser mulher, além do que cada pessoa tem várias identidades, que por vezes, são contraditórias, resultado do pensamento dicotômico sobre ser homem ou mulher. As identidades são construídas segundo as experiências de vida, e se a identidade é algo pessoal, a imposição torna-se violência de gênero.

O papel da família foi importante na vida esportiva das atletas. Em que pese a resistência da família manifestada no início da inserção na prática do futebol, as esportistas contaram com o incentivo e apoio familiar de diferentes maneiras, o que poderia se considerar como um dos fatores que influiu tanto no começo da prática desde cedo, quanto na permanência e continuidade delas no esporte. Foi primordial a presença do pai como um educador esportivo, devido que este assumiu o papel de incentivador através de lições esportivas, por meio das quais transmitia seus conhecimentos relacionados ao futebol, principalmente nos momentos de lazer; saberes facilmente neles encontrados, pelo fato deste esporte ser legitimado para os homens nessa cultura. Sobre este mesmo tema García, Lagardera e Puig (2002) expressam que socialmente o pai é o agente socializador do habitus esportivo, fundamentalmente pelas atribuições de masculinidade dadas ao esporte, em especial de força e virilidade. Segundo Fredricks e Eccles (2004, citado em Nunomura e Oliveira, 2014), o envolvimento dos pais na vida esportiva dos filhos, permite que eles cumpram com vários papeis tais como técnicos, motoristas, financiadores, espectadores e chefe de torcida, funções encontradas nos relatos das atletas, no relacionado ao incentivo familiar.

Os exemplos relatados pelas atletas de desaprovação de parte de algum familiar, indicam que as primeiras barreiras com que as atletas se depararam, se relacionaram com a aceitação familiar do futebol, como sua principal brincadeira ou esporte, sendo estas superadas à medida que algumas jogadoras levavam mais a sério sua prática, ou se envolviam mais nas competições e treinos. Com oposição à prática dos futebóis ou sem ela, o apoio da família se evidenciou desde cedo. Uma forma de incentivar foi, por exemplo, na busca de um local específico para a aprendizagem do esporte, influenciado, na maioria das vezes, pela qualidade ou pelo talento observado nas atletas. Segundo Bloom (1985, apud Lorenzo e Sampaio, 2005), quando os pais percebem um talento ou facilidade em seus filhos para realizar algum esporte, eles procuram um local de aprendizagem no qual esses talentos sejam desenvolvidos. Evidentemente, a participação e incentivo familiar no esporte, principalmente dos pais, é essencial, e por vezes, determinante, para a permanência e o nível de sucesso na carreira esportiva conforme apresentado nos estudos realizados por Nunomura e Oliveira (2014). Algo similar foi constatado na experiência das atletas de futsal da equipe da UFRGS, mas aqui o sucesso esportivo é difícil de classificar em um contexto social de desvalorização dos futebóis como é o brasileiro, podendo dizer que o fato delas permanecerem dentro do esporte, participarem de quase todos os campeonatos existentes dessa categoria, e terem desenvolvido capacidades destacáveis, segundo suas narrativas, é algo obtido, em grande parte, com o apoio de seus pais, manifestado de diferentes maneiras. 
Com relação aos futebóis no espaço escolar, é importante mencionar o pensamento de Louro (1997), quando diz que dentro da escola os espaços são delimitados, servindo-se "de símbolos e códigos, ela afirma o que cada um pode (ou não pode) fazer, ela separa e institui. Informa o 'lugar' dos pequenos e dos grandes, dos meninos e das meninas" (p. 58). A divisão nas aulas de educação física reforçava de forma simbólica o lugar das meninas dentro do mundo esportivo. A prática esportiva foi uma manifestação da naturalização da divisão de gênero em todas as estruturas, inclusive na educativa.

As experiências dentro da escola foram na sua maioria satisfatórias quando de parte dos meninos, pois eles, tomando como principal referência a habilidade delás para jogar futebol, as incluíam no seu grupo depois de conferida tal capacidade. É importante destacar a importância da habilidade para serem incluídas no jogo. A habilidades se desenvolvem desde cedo nos diversos espaços de socialização, o que muitas vezes nas meninas não se evidencia, por causa do controle com relação à norma de gênero. Este aspecto permite questionar as diferenças na prática dos futebóis entre meninas e meninos, dado que muitas vezes se justifica a partir da biologia, umas diferenças que são ampliadas por meio das interdições culturais. Nas experiências das atletas entrevistadas, o (des)interesse, a diferença da habilidade entre meninas e meninos para o futebol, e as caraterísticas consideradas biológicas, foram os principais motivos geradores da segregação sexual nas aulas de Educação Física, todos estes produzidos e constituídos socialmente, tendo como referência a falta de incentivo da prática nas meninas, o que resulta numa desigualdades nas habilidades. Desse modo, o corpo é visto como um lugar sobre o qual podem ser aplicadas diversas proibições para controlar aos indivíduos, "dele consegue-se retirar movimentos, atitudes, gestos e rapidez" (Silva, 2008, p. 95). Pensar na forma como a escola, através da Educação Física, controla e produz determinados corpos, por meio de práticas de separação entre meninos e meninas, ajuda na compreensão de como as desigualdades sociais são construídas na cotidianidade, e como a escola está contribuindo com este propósito.

No que respeita à participação nos futebóis, este surgiu na vida das atletas em todas as dimensões expostas por Tubino (2001), sendo elas: Esporte Escolar, Esporte Participação, Esporte Performance. A dimensão da esporte participação se apresentou na vida das atletas como lazer, protagonizando suas brincadeiras na rua, seus espaços de sociabilidade e seus momentos de recreio. O esporte-educação aparece quando participaram nas aulas de Educação Física, nas competições esportivas escolares, nas suas estadias e aprendizados nas escolinhas, clubes e projetos sociais, sendo por vezes simultâneos estes espaços de participação nas suas etapas de vida. A dimensão de alto rendimento apresenta uma alta complexidade na sua definição, pois, algumas delas participaram em escolinhas/clubes de futebol como Grêmio e Internacional, e em clubes de futsal considerados profissionais no senso popular, que participam da maior competição de futsal do Estado e Ihes permite mostrar se como atletas para uma futura convocação dos torneios de futsal organizados pela FIFA, embora carecesse de outras caraterísticas atribuídas ao esporte espetáculo.

O contexto mercantilista, o fato de ser considerado um esporte para homens, os significados simbólicos atribuídos em alguns contextos a essa prática, e outros fatores sociais permitem que existam mais escolinhas de futebol e de futsal para meninos, espaços que algumas meninas procuram devido a estas circunstâncias. Sendo que a modalidade quando são mulheres as que jogam parece não resultar tão atrativa para as pessoas que gostam dos futebóis, torna-se mais difícil encontrar patrocinadores, pois eles querem mostrar sua marca comercial para uma maior quantidade de espectadores possíveis. Sem patrocinadores não há recursos para pagar salários às jogadoras, uniformes, transporte, médicos, comissões técnicas, etc. Da mesma forma, a mídia dá visibilidade para os eventos esportivos que maior público atrai e isso também é 
importante para conseguir patrocínio, pois se a mídia visibiliza, suas marcas também logram esse cometido. Aqui radica a importância do papel do Estado para promover e financiar estas práticas esportivas que estão atravessadas de significados culturais, e que por si mesmas parecem difícil de serem transformadas.

Com relação aos significados atribuídos à prática esportiva, estes foram sustentados com base nas experiências futebolísticas, as quais aportaram na construção das suas identidades como mulheres, como esportistas e como universitárias. De acordo com Mazo, Silva e Lyra (2010), a produção de identidades é feita no interior de contextos sociais que determinam a posição dos agentes e é por isso que "guiam suas representações e suas escolhas" (p. 2).

Amizade, família, vínculo, competição, foram as palavras mais usadas para descrever o que significa para as atletas de futsal da UFRGS estarem ali. Nem sempre jogar os futebóis significou o mesmo para elas, isso estava submetido ao espaço, e às pessoas com as quais praticavam o jogo, se era na escola, na rua, em um time, em um clube, em uma escolinha. Também dependeu dos vínculos afetivos criados entre as atletas do time e das prioridades que foram se tornando diferentes segundo a idade. Silveira (2008) realizou um estudo etnográfico num time de futsal praticado por mulheres em Porto Alegre, no qual analisou o esporte, a homossexualidade e a amizade, com o objetivo de compreender o associativismo feminino no contexto de lazer, em um esporte socialmente considerado masculino como é o caso do futsal. A autora observou que um dos aspectos que permite manter o associativismo esportivo foram as relações de amizade que se construíam dentro desse universo, ao ponto de extrapolar os limites relacionados com o esporte, envolvendo-se em outras esferas da vida. De igual forma, as jogadoras desse time construíram relações pautadas em uma lógica familiar, como foi observado no relato de uma das atletas, que considera uma de suas colegas como uma irmã.

A banda de pagode criada pelo time da UFRGS, constitui-se mais um elemento de significados da prática esportiva. Por meio da música é possível trazer as manifestações culturais identitárias de grupos específicos, neste caso, elas como mulheres e futebolistas. De acordo com Trotta (2013), o pagode é um produto cultural que emergiu da periferia, associado a um conjunto de ideias sobre o popular que "tematiza e elabora significados sobre esse local físico e simbólico" (p. 162). Dessa forma, esta música, como manifestação da cultura brasileira cumpre uma função política, pois através dela se tenta inverter a desvalorização atribuída socialmente para os moradores desse espaço (Trotta, 2013). A diferença do significado cultural do pagode, no qual as temáticas visam à positivação de um grupo social de classe com base na oposição centro/periferia (Trotta, 2013), através desta banda as integrantes manifestam uma luta política de gênero ante a oposição mulher/homem e feminino/masculino dentro dos futebóis. A banda musical de pagode é o fato mais explícito de que estar em uma equipe de futsal não se reduz simplesmente a fazer esporte, pois a partir dessa associação as possibilidades de sociabilidade e de luta ante um objetivo comum se ampliam.

Por outro lado, as boas amizades, os vínculos criados através da prática de futsal, são um fator importante para continuar no time, e criar uma identidade grupal com base nele. Estas relações afetivas são muito importantes para o logro dos objetivos competitivos e para a coesão e identificação grupal. As experiências das atletas como jogadoras dos futebóis foram, embora plurais, particulares. Estar em um time, compartilhar com pessoas, competir, treinar, não significou o mesmo para elas em todos os lugares. Cada equipe marcou nelas sua própria subjetividade, reflexividade e transformação. 
Pertencer a uma equipe de futsal ou de futebol foi diferente em cada um desses grupos de pessoas, os sentimentos foram diversos, suas relações entre colegas, seus vínculos, objetivos, motivações, significados etc. Larrosa (2011) enfatiza que a experiência não é algo que se faz, mas algo que se passa a alguém, sendo que a prática pode ser um lugar de experiência. Aqui é necessário interromper a lógica da ação, para o sujeito passar pela experiência, nas suas palavras: "a experiência não está do lado da ação, ou da prática, ou da técnica, mas do lado da paixão" (p. 22). A experiência é um processo totalmente subjetivo e particular que se padece, ao mesmo tempo em que não é intencional. 0 esporte fez parte de seu estilo de vida, da constituição das suas identidades de gênero e da relação com os outros. É um espaço de sociabilidade importante na construção de vínculos, de amizade, de paixões e tornou-se numa possibilidade política de expressar suas inconformidades como mulheres.

\section{CONCLUSÕES}

No percurso acadêmico realizado nesta pesquisa, foi possível conhecer vários aspectos das histórias de vida das atletas de futsal da Universidade Federal do Rio Grande do Sul dentro da prática esportiva. A categoria de gênero como uma dimensão transversal nas relações sociais foi analisada neste trabalho, identificando-se através dessas trajetórias as representações sociais relacionadas com as feminilidades e as masculinidades que permeiam no contexto esportivo dos futebóis.

Da mesma maneira, constatou-se as desigualdades sociais que ainda existem entre homens e mulheres no âmbito esportivo, originadas por diversos aspectos de índole social e cultural, como por exemplo, as relações de poder construídas no interior da sociedade cujo poder simbólico está desequilibrado em favor dos homens. Esta situação dificulta em algumas mulheres, mais que em outras, o acesso à prática dos futebóis nos diferentes contextos nos quais se inter-relacionam.

As atletas iniciaram sua relação com os futebóis jogando na rua principalmente com meninos, sendo na maioria das vezes as únicas meninas que participaram nesse espaço. Vale à pena nos perguntarmos: por que poucas mulheres/meninas gostam de jogar futebol em um país como o Brasil, onde este esporte é tão popularizado e visto como referência para a construção da identidade nacional?

Esta é uma área problemática analisada neste estudo, a qual foi explicada teoricamente através da discussão sobre algumas das razões pelas quais o futebol é considerado na sociedade brasileira um jogo de homens e para homens, enfatizando principalmente em fatores econômicos e políticos, assim como nas representações de gênero que indicam o que é ser homem e mulher neste contexto social. De igual forma, se apresentou como o jogo de alguns esportes, especificamente de futebol, é uma prática que simbolicamente aporta na construção dessa representação. Geralmente, as atletas entrevistadas narraram a forma como foram influenciadas por homens ou meninos, (pais, irmãos, primos, tios, amigos, professores) para se aproximarem ao jogo de futebol, sendo eles os que mais são incentivados neste contexto social para praticá-lo.

A situação das mulheres que jogam futebol é diversa, visto que os diferentes contextos sociais se caracterizam por particularidades na forma como as representações sociais são interiorizadas nos sujeitos. Por esse motivo, nem todas as atletas que participaram desta pesquisa manifestaram experiências problemáticas diretas durante sua trajetória esportiva. No entanto, outras situações relatadas demonstraram que socialmente é mais difícil para as mulheres serem reconhecidas socialmente por sua participação no jogo dos futebóis. 
No contexto escolar, as atletas vivenciaram a segregação sexual como uma estratégia dos/das professores/as para oferecer as aulas de Educação Física. Esta foi outra área problemática analisada, visto que isso impediu que algumas das atletas levassem a cabo o jogo do futebol nesse momento específico de sua formação. A preferência das suas colegas por outros esportes como o voleibol e o handebol, permitiu analisar porque alguns esportes se consideram mais aptos para mulheres do que outros e a forma como historicamente esta situação foi se construindo no Brasil desde o início da Educação Física no contexto escolar, identificando as representações de gênero desde a época em que implementaram essas aulas como obrigatórias nas instituições educativas. Este tipo de estratégias reforça as crenças relacionadas com os corpos, pois a separação teria uma justificativa de base biológica, referindo que os corpos dos homens e das mulheres são vistos como naturalmente diferentes, requerendo práticas esportivas também diferentes.

De igual forma, algumas das atletas entrevistadas narraram sua facilidade para participar do futebol no recreio escolar, principalmente em função da sua habilidade para praticar este esporte. Enquanto outras manifestaram quão difícil foi agir nesse lugar pelo fato de se sentirem diferentes por serem as únicas meninas que jogavam ou que queriam participar do jogo, devido ao fato de que muitas outras meninas não sentiam o mesmo interesse por este esporte. O fato de serem meninas que gostavam de um esporte que, socialmente, tem uma conotação de masculinidade fez com que algumas delas passassem por um controle social, ou como foi chamado por Bento (2011), o controle produtor que infere expressões como "Isso não é coisa de menina!". Ou seja, que produz masculinidades e feminilidades. Algumas das atletas manifestaram a forma como esse controle produtor surgiu nas suas relações sociais na escola, especialmente com as colegas que questionavam seu gosto pelo futebol. O interessante foi identificar que nem todas passaram pelas situações de exclusão, e que algumas tiveram experiências esportivas relacionadas com os futebóis mais satisfatórias, ou seja, não problemáticas.

A sub-representação de meninas/mulheres que jogavam os futebóis no contexto escolar, por vezes, impedia que elas encontrassem uma equipe para participar das competições. As poucas escolinhas de futebol ou de futsal existentes neste período de suas vidas era um obstáculo para que se formassem esportivamente e desenvolvessem suas habilidades físicas específicas, fato que levou algumas das atletas a fazer parte de escolinhas de futebol para meninos com algumas particularidades relacionadas ao fato de serem as únicas meninas em meio deles.

As jogadoras de futsal da UFRGS manifestaram que o esporte transcendia a prática em si, visto que suas diversas experiências dentro dele Ihes permitiram criar laços de amizade e a construção de outros significados que marcaram suas escolhas e formas de ver o mundo. As atletas de futsal entrevistadas relataram o que significa para elas serem mulheres que jogam os futebóis, e as lutas que por meio do esporte empreenderam para se posicionarem como mulheres que também podem seguir as suas paixões, apesar das normas culturais de gênero que colocam os futebóis como menos aptos para elas. A sociabilidade, resultado do associativismo esportivo no time de futsal da UFRGS, Ihes permitiu outras experiências além da prática em si, que envolve sentimentos, emoções, lutas e significados.

Estes estudos se fazem com o objetivo de dar reconhecimento às mulheres por suas capacidades esportivas, pelo aporte à história, por seu esforço e sacrifício para superar os desafios que o esporte exige. Que trabalhos como este aportem na discussão dentro do futebol de que mulher também pode, também tem o direito, também existe. 


\section{REFERÊNCIAS}

Altmann, H. (1998). Rompendo fronteiras de gênero: Marias (e) homens na Educação Física. Belo Horizonte: Dissertação (Mestrado em Educação) - Curso de Pósgraduação em Educação. Universidade Federal de Minas Gerais.

Altmann, H. (2009). Currículo, gênero e esportes. Em Costa Ribeiro, P. R.; Santos Da Silva, M. R.; Goellner, S. Corpo, gênero e sexualidade (pp. 57 - 65). FURG.

Altmann, H.; Reis, H. (2013). Futsal feminino na América do Sul: trajetórias de enfrentamentos e conquistas. Movimento, 19(3), 211-232. https://seer.ufrgs.br/ Movimento/article/view/35077

Andrade, L. (2015). Depoimento de Laura Giovana dos Santos Andrade. Projeto Garimpando Memórias. Centro de Memória do Esporte ESEFID/UFRGS. https:// www.lume.ufrgs.br/handle/10183/156369

Araújo, M. L.; Silveira, R. D. (2013). As trajetórias de jogadoras de futebol: processos de socialização em jogo. Espaço Plural, 29(14), 271-297. http://cev.org.br/biblioteca/ as-trajetorias-de-jogadoras-de-futebol-os-processos-de-socializacao-em-jogo/

Bertoli, L. (2014). Depoimento de Luiza Loy Bertoli. Projeto Garimpando Memórias. Centro de Memória do Esporte - ESEFID/UFRGS. https://www.lume.ufrgs.br/ handle/10183/149067

Bardin, L. (1986). El análisis de contenido. Akal.

Bento, B. (2011). Na escola se aprende que a diferença faz a diferença. Estudos Feministas, 19(2)19, 548- 559.

Dornelles, P. G. (2011). Marcas de gênero na Educação Física Escolar: a separação de meninos e meninas em foco. Motrivivência, 23(37), 12-29. https://periodicos.ufsc. br/index.php/motrivivencia/article/view/24447

Espirito Santo, R. (2015). Depoimento de Rafaela Cavalheiro do Espirito Santo. Projeto Garimpando Memórias. Centro de Memória do Esporte ESEFID/UFRGS. https:// www.lume.ufrgs.br/handle/10183/148589

Fagundes, T. (2015). Depoimento de Thayná Lima Fagundes. Projeto Garimpando Memórias. Centro de Memória do Esporte. ESEFID/UFRGS. https://www.lume.ufrgs. br/handle/10183/156368

Fernandes, V.; Mourão, L. (2013). Representações de feminilidades no boxe para mulheres. Seminário Internacional Fazendo Gênero, 10, 1-12. http://www.fg2013. wwc2017.eventos.dype.com.br/resources/anais/20/1381509139 ARQUIVO VeraFernandes.pdf

Ferrarotti, F. (2011). Las historias de vida como método. Acta Sociológica, (56), 95-119. http://www.revistas.unam.mx/index.php/ras/article/view/29459/27408 
García, M. F.; Lagardera, F. O.; Puig, N. B. (2002). Cultura deportiva y socialización. En García, M. F.; Lagardera, F. O.; Puig, N. B. Sociología del Deporte. 2. ed. Alianza. https://dialnet.unirioja.es/servlet/articulo?codigo $=2104094$

Giozza, R. R. (2014). Depoimento de Rafaela Rocha Giozza. Projeto Garimpando Memórias. Centro de Memória do Esporte ESEFID/UFRGS. https://www.lume.ufrgs. br/handle/10183/156367

Goellner, S. V. (2007). Feminismos, mulheres e esportes: questões epistemológicas sobre o fazer historiográfico. Movimento, 2(13), 171-196. http://seer.ufrgs.br/ Movimento/article/viewFile/3554/1953

Goellner, S. V.; Muhlen, J. C. ; Maurmann, A.; Romero, C. S. (2007). Garimpando Memórias: Esporte, Educação Física, Lazer e Dança no Rio Grande do Sul. Em Goellner, S. V.; Jaeger, A. A. Garimpando Memórias: Esporte, Educação Física, Lazer e Dança. UFRGS. https://www.lume.ufrgs.br/bitstream/handle/10183/81279/000606390. pdf?sequence $=1$

Hernández-Sampieri, R; Fernández-Collados, C; Baptista-Lucio, M. (2010). Metodología de la Investigación (5 ed.). McGrawHill.

Joras, P. (2015). Futebol e mulheres no Brasil: a história de vida de Aline Pellegrino. (Dissertação de Mestrado). Escola de Educação Física, Fisioterapia e Dança, Universidade Federal de Rio Grande do Sul.

Larrosa, J. (2011). Experiência e alteridade em Educação. Revista Reflexão e Ação, 19(2), 04-27. http://dx.doi.org/10.17058/rea.v19i2.2444

Lorenzo, A.; Sampaio, J. (2005). Reflexiones sobre los factores que pueden condicionar el desarrollo de los deportistas de alto nivel. Apuntes Educación Física y Deportes, 80(2), 63-70. https://dialnet.unirioja.es/servlet/articulo?codigo $=1183654$

Louro, G. (1997). Gênero, Sexualidade e Educação. Uma perspectiva pós-estruturalista. Petrópolis: Vozes.

Machado, J. D. L. (2015). Depoimento de Jaqueline de Lima Machado. Projeto Garimpando Memórias. Centro de Memória do Esporte. ESEFID/UFRGS. https://www.lume.ufrgs. $\underline{\mathrm{br} / \mathrm{handle} / 10183 / 149086}$

Machado, L. S. (2015b). Depoimento de Lícia Sobrosa Machado. Projeto Garimpando Memórias. Centro de Memória do Esporte. https://www.lume.ufrgs.br/ handle/10183/148631

Máximo, R. F. (2015). Depoimento de Renata Fragoso Máximo. Projeto Garimpando Memórias. Centro de Memória do Esporte. ESEFID/UFRGS. https://www.lume.ufrgs. $\underline{\mathrm{br} / \mathrm{handle} / 10183 / 156372}$

Mazo, Z.; Silva, C. F. D.; e Lyra, V. B. (2010). As mulheres no cenário do associativismo esportivo em Porto Alegre/RS na transição do século XIX para o XX: alternativas de sociabilidade e lazer para elas. Licere, 3(13), 1-25. https://periodicos.ufmg.br/ index.php/licere/article/view/798 
Moreira, M. D. F. S.; Cunha, A. M. G. D. (2008). Garotas no futebol: trajetórias de gênero e sexualidade. Fazendo Gênero, Corpo, Violência e Poder, (8), 1-8.

Mota, M. M. (2014). Depoimento de Miraildes Maciel Mota (Formiga). Guerreiras Projet. Centro de Memória do Esporte. ESEFID/UFRGS.

Nunomura, M.; Oliveira, M. S. (2014). A participação dos pais na carreira das atletas femininas de ginástica artística: a perspectiva dos técnicos. Revista Brasileira de Educação Física e Esporte, 01(28), 125-134. http://dx.doi.org/10.1590/S1807$\underline{5092014005000004}$

Pereira, L. M. L. (2000). Algumas reflexões sobre histórias de vida, biografias e autobiografias. História Oral, (3), 117-127. http://revista.historiaoral.org.br/index. php?journal $=$ rho\&page $=$ article\&op $=$ view $\&$ path $\% 5 B \% 5 D=26 \& p a t h \% 5 B \% 5 D=20$

Pinho, C. D. F. (2015). Depoimento de Carolina Dertzbocher Feil Pinho. Projeto Garimpando Memórias. Centro de Memória do Esporte. ESEFID/UFRGS. https://www.lume.ufrgs. br/handle/10183/149083

Polese, P. (2015). Depoimento de Vanessa Prestes Polese. Projeto Garimpando Memórias. Centro de Memória do Esporte. ESEFID/UFRGS. https://www.lume.ufrgs. $\underline{\mathrm{br} / \mathrm{handle} / 10183 / 148628}$

Ramos, S. D. S. (2015). Depoimento de Suellen dos Santos Ramos. Projeto Garimpando Memórias. Centro de Memória do Esporte. ESEFID/UFRGS. https://www.lume.ufrgs. br/handle/10183/149071

Ribas, L. O. (2015). Depoimento de Leticia Oscar Ribas. Projeto Garimpando Memórias. Centro de Memória do Esporte. ESEFID/UFRGS. https://www.lume.ufrgs.br/ handle/10183/156374

Scott, J. W. (1995). Gênero: uma categoria útil de análise histórica. Educação \& Realidade, 20(2), 71-99.

Shaw, S. (2007). Gender in sport management: a contemporary picture and alternative futures. In: Aitchison, C. C. Sport and Gender Identities. Masculinities, femininities and sexualities, 74-89.

Silva, M. V. P. D. (2008). Controle e normalização: Michel Foucault e a relação entre corpo e poder. Revista de Teoria Política, Social e Cidadania, (03), 87-98. http:// www.fbb.br/media/Publica\%C3\%A7\%C3\%B5es/Domus/5\%20Vinicius\%200k\%20 Foucault\%20Domus\%20corrig\%20por\%20ele.doc.pdf

Silveira, R. D. (2008). Esporte, homossexualidade e amizade: estudo etnográfico sobre o associativismo no futsal feminino. (Dissertação de Mestrado). Escola de Educação Física, Fisioterapia e Dança, Universidade Federal de Rio Grande do Sul. https:// www.lume.ufrgs.br/handle/10183/13800

Simmel, G. (2002). Cuestiones fundamentales de Sociología. Gedisa. 
Sousa, E. S. D.; Altmann, H. (1999). Meninos e meninas: expectativas corporais e implicações na educação física escolar. Cadernos Cedes, 48(19), 52-68. http:// www.scielo.br/scielo.php?script=sci arttext\&pid=S0101-32621999000100004\&lng =en\&nrm=iso

Trotta, F. D. C. (2013). Entre o Borralho e o Divino: a emergência musical da "periferia". Galáxia, (26), 161-173. http://dx.doi.org/10.1590/S1982-25532013000300013

Tubino, M. (2001). Política Nacional do Esporte. http://portal.esporte.gov.br/arquivos/ conselhoEsporte/polNacEsp.pdf

Wenetz, I.; Stigger, M. P.; Meyer, D. E. (2013). As (des)construções de gênero e sexualidade no recreio escolar. Revista Brasileira de Educação Física e Esporte, 27(1), 117-128. http://www.scielo.br/scielo.php?pid=S1807-55092013000100012\&script=sci abstract\&tlng=pt

Zambrini, L.; Ladevito, P. (2009). Feminismo filosófico y pensamiento postestructuralista: teorías y reflexiones acerca de las nociones de sujeto e identidad femenina. Revista Latinoamericana, (2), 162-180. 